PAPER

\title{
Late mortality after head injury
}

\author{
B Pentland, L S Hutton, P A Jones
}

J Neurol Neurosurg Psychiatry 2005;76:395-400. doi: 10.1136/jnnp.2004.037861

See end of article for authors' affiliations

...................

Correspondence to:

Dr B Pentland, Astley

Ainslie Hospital,

Edinburgh EH9 $2 \mathrm{HL}$;

Brian.Pentland@lpct.scot.

nhs.uk

Received 9 February 2004

In revised form 8 June 2004

Accepted 10 June 2004

\begin{abstract}
Objectives: To investigate mortality trends in a cohort of people admitted to a regional head injury unit with all severities of injury in the calendar year 1981.

Methods: A computerised database with details of 1919 admissions was compared with deaths registered by the NHS Central Register, Scotland for the years 1981 to mid-2002. Death certificate information for matches was analysed.

Results: The 1919 admissions referred to 1871 individuals, comprising 93 severe, 205 moderate, and 1573 minor injuries according to Glasgow coma scale criteria. There were 57 deaths (42 severe head injuries, eight moderate, seven minor) during the initial admission, and 340 (six severe, 33 moderate, 301 minor) in the subsequent years. Substance abuse, principally alcohol, was a factor in 37 deaths, suicide accounted for 20, and accidents for 25 . The great majority of these latter deaths were in people under the age of 70 years.

Conclusion: Premature deaths after predominantly minor head injury are commonly alcohol related or the result of suicide or accidents.
\end{abstract}

A ccidents are the most common causes of death in young adults in the United Kingdom ${ }^{1}$ and about half the trauma deaths are caused by head injury. ${ }^{2}$ Many deaths occur before admission to hospital ${ }^{3}$ and most of those occurring after admission happen within the first month. ${ }^{4}$ There have been few studies of longer term mortality trends after traumatic brain injury. Those that have been reported refer to selected populations such as war veterans, ${ }^{4-6}$ children and young adults, ${ }^{7}$ or those classified as sustaining severe injuries. ${ }^{89}$ In Edinburgh in 1981, a single head injury unit staffed by neurosurgeons received people of all ages with all severities of head injury requiring hospital admission. In that year there were 1959 admissions to the unit and a report on a detailed survey of 1919 cases was published. ${ }^{10}$ The severity categories of these cases were 1616 minor, 210 moderate, and 93 severe. $^{10}$

In this report we describe an investigation into mortality trends in this population by matching the 1981 database with death certificates from the national register.

\section{METHODS}

The 1981 survey details of all admissions to the head injury unit of the Royal Infirmary, Edinburgh, are held on a computer database. These include demographic information, causes of injury, dates of admission and discharge or death, conscious level and other clinical details, radiology results, any surgical operations undertaken, and outcome at discharge. The NHS Central Register (NHSCR), Edinburgh, is funded by the Scottish Executive Department of Health and is linked by computer to records of births, deaths, and marriages held by the General Register Office of Scotland. Staff of the NHSCR maintain a central record of all patients resident in Scotland who have NHS numbers in Scotland, England, Wales, and Northern Ireland and are linked to the NHSCR for England and Wales at Southport, UK.

The 1981 survey database was sent to the NHSCR on compact disc in the summer of 2002 and they returned possible matches of people with the same date of birth with forenames, postcodes, and date, cause(s), and place of death. This information was then checked against the other data from the survey, particularly residence, to confirm matches. The original survey database coded dates of birth numerically with two digits for the year. Thus those born in the 19th century would not be so identified (for example, the date of birth of an individual who was born on 4 October 1893 would appear as 04/10/93). The NHSCR recorded four digits for the year of death so that matches would not occur for people with dates of birth before 1 January 1900. This means that the matches reported in this study refer to people born on or after this date and aged under 81 years at the time of injury. The exception to this is the report of those dying on the unit and reported in the original survey. For these the original database recorded dates of death and these were rechecked against the NHSCR with the 19th century dates of birth.

The NHSCR provided International Classification of Disease (ICD) codes from death certificate information using ICD-9 for 1981 to 1999 and ICD-10 from the year 2000 onwards. From this information, certified causes of death were grouped into five system categories and six non-system categories for ease of reporting. The five system categories were: cardiovascular, neoplastic, respiratory, cerebrovascular, and other system disease/disorder. The six non-system categories were: alcohol related, drug related, suicide, epilepsy, accidental, and those attributed to the late effects of injury. Where two codes were given on a person's certificate and these two codes were from different categories they were recorded separately in both.

In this report we review the 57 deaths that occurred in the head injury unit in the original survey, and then consider the deaths that occurred after discharge from the unit. We describe these latter post-discharge deaths in relation to the severity of injury (as severe, moderate, and minor according to Glasgow coma scale (GCS) scores of 3-8, 9-12, and13-15, respectively) and we discuss deaths from non-system causes in more detail.

\section{RESULTS}

As previously reported, there were 1959 admissions to the regional head injury unit in 1981 but insufficient information was available in 40 cases-all brief admissions-so that 1919 cases were included in the database..$^{10}$ Thirty eight patients had two or more admissions, accounting for 48 repeat admissions. Thus the 1919 admissions were of 1871 individual patients. Where repeat admissions occurred, the 
most severe category was taken for the purpose of relating death to severity. Therefore, within the 1871 patients, 93 were severe, 205 moderate, and 1573 minor.

In addition the survey database had incomplete date of birth information on 21 patients (nine moderate and 12 minor cases). This revised the number of cases where matches were possible to 1850 (93 severe, 196 moderate, and 1561 minor)

The NHSCR provided 476 possible matches, of which 397 were confirmed.

\section{Deaths in the original survey}

Fifty seven individuals died during their admission to the head injury unit. The original survey specifically excluded from the database people declared as brain dead on arrival at the hospital or in the accident and emergency department, and did not include patients transferred to other units who subsequently died. The 57 deaths consisted of 42 severe injuries, eight moderate, and seven minor. The sex and age of these patients are summarised in table 1 .

Of these original deaths while still in the head injury unit, all the minor and moderate group deaths occurred in 1981. In the severe group, 39 died in 1981, two in 1982, and one in 1983, having remained in the unit until death.

Table 1 also summarises the cause of death according to the death certificate records of ICD-9 codes. The two severe cases coded as late effects died 1 year 4 months and 2 years post-injury. The minor injury case recorded as dying from this cause was a 64 year old man who died three days after admission and who was also coded as suffering from respiratory failure. Those categorised as other were a 74 year old woman classified as having a moderate injury who suffered a stroke and died one month after admission; and two women aged 76 and 80 years who died of myocardial infarction and cardiac failure, respectively, both within 48 hours of admission.

\section{Deaths post-discharge from the unit}

In all, 340 further deaths were recorded by the NHSCR. Figure 1 summarises these deaths according to year and whether death occurred under the age of 70 years or at age 70 years or older. As noted above, those aged over 80 years at the time of injury were unlikely to be matched so that the numbers of elderly deaths are likely to be considerably less than the actual number of individuals who died.

\section{Deaths post-discharge related to severity of injury}

Fifty one of the 93 patients categorised as severe survived to be discharged from the unit. Six of these died subsequently in the ensuing 20 to 21 years. One 20 year woman died 81 days after injury, having been transferred to another hospital; the cause of death was recorded as motor vehicle traffic accident. Three men were reported as dying of the late effects of injury. They survived 11 months, one year six months, and five years post-injury and were aged 20,34, and 15 years, respectively, at the time of death. The two remaining cases, both men, were aged 64 and 84 years at death from pneumonia and respiratory failure, and they had survived for two years, three months and almost 13 years, respectively, after head injuries. Thus there is no clear relation between the original injury and the cause of death in these two of the six deaths.

There were 33 matches for deaths in the 188 survivors of moderate injury. The median age at death for this group was 70 years (mean 67; range 20 to 88). Ten of the 33 had two diagnoses at death, so 43 causes of death apply. Of these, 12 were cardiac, 10 respiratory, five neoplastic, and seven involved other systems. Two were alcohol related, five accidental causes, one suicide, and one epilepsy. None of the moderate group deaths was recorded as a late effect of injury. However, two of the five accident deaths (men aged 69 and 70 years) were likely to refer to the original injury. These deaths both occurred soon after discharge from the head injury unit to other hospitals.

There were 1573 people with minor injuries, and of these accurate date of birth information was available on 1561 . There were 308 matches for this group, seven of whom died in the head injury unit, leaving 301 subsequent deaths. The age of death in this group was less than 70 years in $144(48 \%)$ and 70 years or more in 157 (52\%). Vascular diseases, respiratory disorders, and neoplasia were the commonest recorded causes of death. However, deaths in this group included 35 that were either alcohol or drug related, 19 accidents, 19 suicides (including four cases of accidental poisoning), and seven where epilepsy was a factor. Of the 19 deaths attributed to accidents, four that occurred in 1981 and one in 1982 probably refer to the original injury. These are described further below.

The frequencies of system and non-system causes of death in the 340 people who died after discharge from the head injury unit are summarised in fig 2. Accidental poisoning is included in the suicides rather than as a drug related cause of death

\section{Deaths post-discharge from non-system causes \\ Alcohol related causes of death}

Thirty one of the 340 deaths had a code for alcohol dependence or alcohol related disorders. All but three of these were aged under 70 years. Thus in 28 (17\%) of the 165 post-discharge deaths in this age group, the death certificates included a code related to alcohol use. In 19 of the 31 cases, an additional diagnosis was given. Five had vascular disease, three cancer; one gastric ulcer; and one renal failure. The

Table 1 Original survey deaths: sex, age, and causes of injury

\begin{tabular}{lllll}
\hline & $\begin{array}{l}\text { Severe head injury } \\
(\mathbf{n = 4 2})\end{array}$ & $\begin{array}{l}\text { Moderate head injury } \\
(\mathbf{n = 8})\end{array}$ & $\begin{array}{l}\text { Minor head injury } \\
(\mathbf{n = 7})\end{array}$ & $\begin{array}{l}\text { Total } \\
\text { (n=57) }\end{array}$ \\
\hline Male & 29 & 3 & 4 & 36 \\
Female & 13 & 5 & 3 & 21 \\
Median age (years) & 31 & 77 & 68 & 55 \\
Age range (years) & 14 to 87 & 41 to 89 & 12 to 80 & 12 to 89 \\
Cause of death & & & & \\
RTA & 26 & 3 & 2 & 31 \\
Fall & 9 & 4 & 2 & 15 \\
Suicide & 3 & 0 & 0 & 3 \\
Assault & 2 & 0 & 0 & 2 \\
Late effect & 2 & 0 & 1 & 3 \\
Other & 0 & 1 & 2 & 3 \\
\hline RTA, road traffic accident. & & & & \\
\hline
\end{tabular}




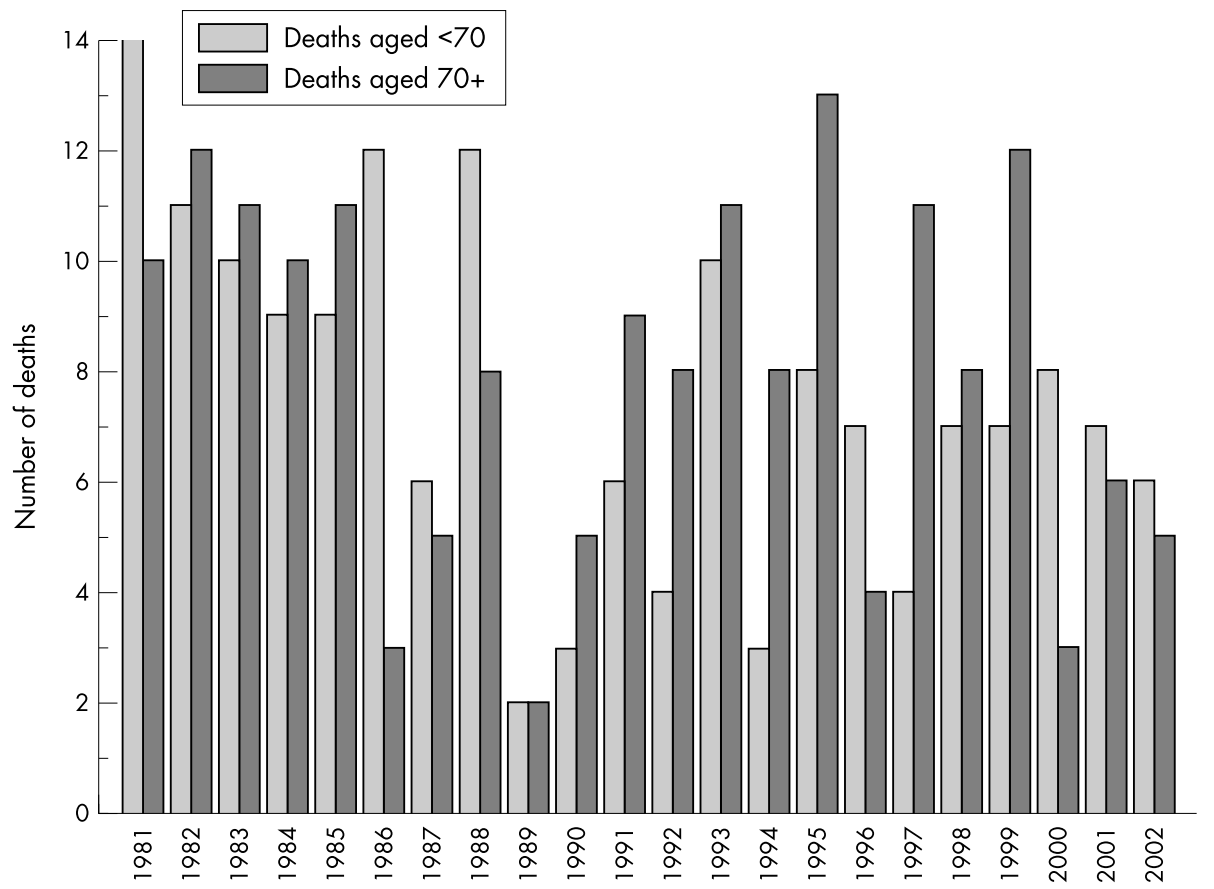

Figure 1 Deaths after discharge from the head injury unit (1982 to 2002).

other nine are described again below, as the additional diagnoses were of death by fire (2), falls (2), choking on a foreign object (2), and single cases each of asphyxia, assault, and epilepsy.

\section{Drug related causes of death}

There were six cases in whom drug abuse was a likely contributory cause of death. Two individuals were reported as drug dependent, both men-one aged 28 and the other 55 at the time of death. The latter was also coded as a case of suicide. Four people, two men aged 33 and 34 and two women aged 29 and 40 years at death, had a certificated cause of death of either immunodeficiency or HIV infection. These cases cannot be confirmed as definitely drug related from the information available.

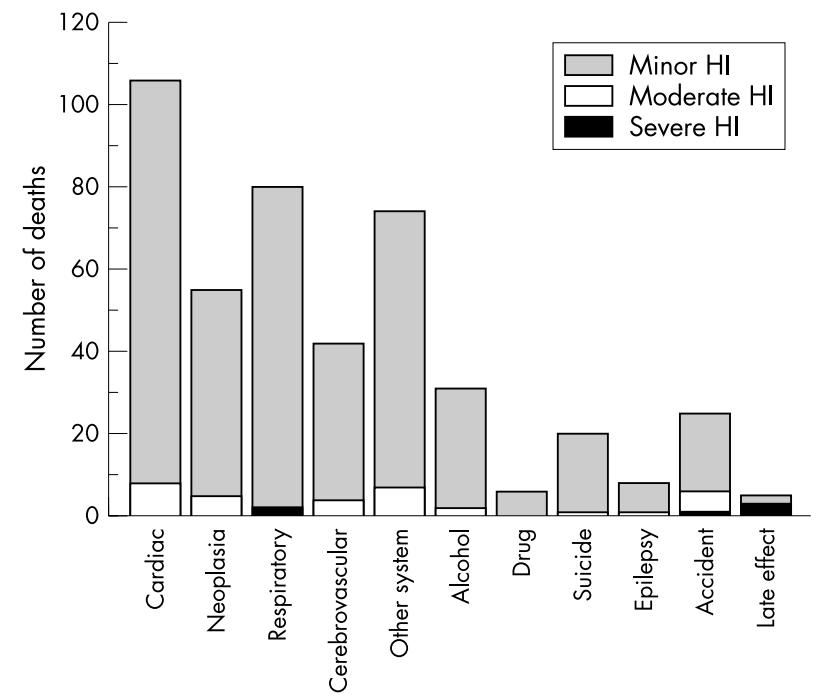

Figure 2 Causes of death in 340 people who died after discharge from the head injury unit.

\section{Suicides}

Sixteen individuals who died after discharge from the head injury unit had a diagnosis of suicide. The median age at death was 39 years (mean 40; range 20 to 72 ), only the one 72 year old being over 70 years and only one being female. Details of the mechanisms of suicide was available in seven of these: overdose of medicines in four, ligature suspension in two, and suffocation by plastic bag in one.

All but one of these 16 cases were categorised as minor original injuries. The exception was the 20 year old man injured as a pedestrian, who was classed as having suffered a moderate injury. However, he was discharged home after an overnight stay having made a good recovery, and his death occurred five months later, indicating that it was a separate incident. Twelve of the remaining 15 were in the unit for less than 24 hours, with the other three having lengths of stay of three, four, and five days.

Four people, two men aged 25 and 27 and two women aged 23 and 45 years at the time of death, were recorded as dying of accidental poisoning.

Table 2 gives the total suicides in Scotland at five year intervals from 1986 to 2001 and for 2002, the mid-year population estimates for these years, and the calculated incidence of suicides for the general population of Scotland. Thus there were approximately 11 to 12 suicides per 100000 .

Table 2 Suicides in Scotland 1986-2002

\begin{tabular}{llll}
\hline Year & $\begin{array}{l}\text { Number of } \\
\text { suicides }\end{array}$ & $\begin{array}{l}\text { Mid-year } \\
\text { population } \\
\text { estimate }\end{array}$ & $\begin{array}{l}\text { Annual incidence of } \\
\text { suicide/100 000 } \\
\text { population }\end{array}$ \\
\hline 1986 & 568 & 5111760 & 11.1 \\
1991 & 525 & 5083330 & 10.3 \\
1996 & 596 & 5092190 & 11.7 \\
2001 & 609 & 5064200 & 12.0 \\
2002 & 636 & 5054800 & 12.6 \\
\hline
\end{tabular}




\section{Epilepsy}

There were eight reports, all in men, of epilepsy as a cause of death. In one case the original injury was classed as moderate and he died aged 72 in 2002 with chronic airways disease as an additional diagnosis. The other seven had had minor injuries with at most a two day admission to the head injury unit. One death of a 31 year old man occurred 38 days after discharge home from an overnight stay following a fall. The other deaths occurred $1,5,11,15,26$, and 18 years postinjury. Ages at death of these cases were 26, 46, 58, 47, 75, and 53, respectively. The 58 year old also had a diagnosis of alcohol dependency, and the 75 year old had suffered a stroke.

\section{Accidents}

There were 25 cases coded as death by accident, seven of which also had an alcohol related coding. The causes were falls (10), motor vehicle accidents (5), fire (4), choking/ asphyxia (3), assault (2), and railway accident (1).

Falls were the cause of death in 10 people. Three of these occurred in 1981 in individuals aged 63, 70, and 78. In all three cases discharge was to another hospital. The 70 year old had a moderate injury and died seven months after transfer. The other two, while classed as minor head injuries, died within a week of discharge from the head injury unit. One further person, a 69 year old man with an injury of moderate severity, died in February 1982, having been discharged from the unit to his local hospital three weeks before death after a four month stay in the head injury unit. In these four cases the fall causing death was almost certainly the cause of the original head injury. The other six falls occurred in the years 1987 to 1999. Three of these were under the age of 70, being 39, 52, and 55 years old at death. The persons aged 39 and 55 years both had an alcohol related cause of death in addition to the fall.

Motor vehicle accidents were cited in three cases in 1981. One followed severe injury of a 20 year old woman who died after transfer to another hospital, as already mentioned above. Two others were most probably the cause of the original injury, although both were classed as minor injuries. One was a 28 year old man who spent less than a day in the unit but had multiple extracranial injuries and was transferred to an orthopaedic ward, dying 28 days later. The other, a 56 year old man, also died 18 days after transfer to another hospital having been in the unit for 35 days. A 61 year old man who died in 1985 as a result of a motor vehicle accident had been admitted in 1981 with a head injury after a fall. The following year a 17 year old died from this cause, his original head injury in 1981 resulting from a fall from a bicycle at the age of 12 . Thus two of the five motor vehicle accident deaths were probably not directly referring to the original injuries.

The four deaths from house fires were of a 46 year old woman and one man aged 55 and two aged 56 years. Two of the men also had alcohol related diagnoses. All four of these individuals had suffered minor head injuries in 1981 .

Three deaths were attributed to choking on a foreign object. These individuals were aged 45,57 , and 62 years at the time of death. The 45 year old and the 62 year old both had alcohol disorders and their original injuries had been classified as minor. The other, while not diagnosed with an alcohol related problem at death, had been admitted on three occasions in 1981, twice with minor and once with moderate head injury, after falls under the influence of alcohol.

The assaults were to a 58 year old man who was stabbed and a 74 year old who was recorded as intoxicated with alcohol at the time of death. Both original injuries were minor.
The one case of a railway accident occurred in 1986 to an 18 year old man. His original injury at the age of 14 years was minor and the result of a pedestrian road accident.

\section{Late effects of injury}

There were five cases of death attributed to the late effects of injury. Three of these were in people categorised as suffering severe head injuries in the original survey but who survived to be discharged from the unit. One occurred in 1986 to a woman then aged 86, who was categorised as suffering a minor injury in 1981. It is not possible to clarify whether the injury referred to on her death certificate was the one which had occurred in 1981. The remaining case was admitted aged 18 years with a minor head injury after an assault on 26 December 1981. He died 10 years later in 1991, so it is probable that he suffered another injury in the interim.

\section{DISCUSSION}

In 1981 the head injury unit at the Edinburgh Royal Infirmary was unusual in the United Kingdom in that, while staffed by neurosurgeons and neuroanaesthetists, it had a policy of accepting all patients with head injury irrespective of their need for surgery. ${ }^{10}$ As a result, much larger numbers of people were admitted with minor injuries, usually requiring overnight observation, than in other neurosurgical units. Thus the study population is more reflective of the pattern of traumatic brain injury in general rather than the more severe categories alone. Despite this there are likely to have been cases of minor or concussive head injury who also suffered significant extracranial injuries and who would have been admitted to orthopaedic or general surgical wards. The advantage, however, of looking at these patients is that all had been assessed as having suffered a traumatic head injury, and details including cause of injury, initial Glasgow coma scale, alcometer readings, discharge destination, and so on, were recorded.

The process of matching the survey population with the NHSCR records of death is not completely reliable in capturing all deaths. As explained above, the 1981 database did not record the dates of birth before 1900. There is also the possibility, indeed likelihood, that incorrect dates of birth were either given or recorded in people confused or intoxicated at the time of admission. Similarly, the names given may have been misspelled-a preferred forename or nickname may have been used or even a false name offered on admission. The constraints of the Data Protection Act prevented the NHSCR from providing surnames for possible matches, but all forenames were provided. Thus it was possible to match some cases where a common abbreviation had been used.

The principal information on causes of death provided by the NHSCR was in the form of ICD codes, but in a proportion of cases some additional details were given. There are potential errors in the translation of death certificate diagnoses into ICD codes and we have no method of checking on the reliability of coding retrospectively. There is also the question of the accuracy of the diagnosis entered on the death certificate, which is dependent on the medical attendant who completes it. It is likely that some diagnoses are overused while others that might pertain are omitted for the sake of the feelings of the deceased's relatives. Thus, for example, myocardial infarction, pneumonia, or general atheroma may be over-represented, while alcoholism, suicide, and psychiatric diagnoses may be under-reported

The deaths from common systematic disorders such as vascular disease and cancer will not be commented upon further but it is of interest to consider the other causes of death in the light of other reports. It should be emphasised that the great majority of the people in this study suffered 
minor traumatic brain injuries. This in itself poses the question as to whether the head injury had any direct relevance to the cause of death over the ensuing 20 or more years. Even if the injury itself was not directly related to the subsequent death, the lifestyle of those suffering head injuries may be. Although the high frequency of accidental deaths, substance abuse related deaths, and suicides reported in this study might be at least partly a consequence of head injury, the population of people who suffer head injury is likely to contain an over-representation of individuals at risk of these causes of death.

Alcohol abuse has long been recognised as a factor predisposing to traumatic brain injury ${ }^{12-15}$ and contributing to longer term cognitive impairments. ${ }^{16}$ It is also common for survivors to revert to or begin abuse of alcohol after injury. ${ }^{17}{ }^{18}$ Of the 165 deaths after discharge and under the age of 70 years in our series, $28(17 \%)$ had an alcohol related cause of death recorded. The fact that alcohol related diagnoses may well be under-reported on death certificates reinforces the significance of alcohol abuse in the head injured population.

The role of drug abuse before and after head injury as a cause of injury and an influence on outcome is less clear than with alcohol. ${ }^{14}$ This is partly accounted for by the less frequent screening for drug as opposed to alcohol use. There was only one individual whose death certificate specifically recorded drug abuse. The inclusion of four cases with immune deficiency or HIV infection as causes of death cannot definitely be assumed to be related to drug abuse. The four cases of accidental poisoning are also placed under drug related causes of death for convenience. These cases might equally well be considered as possible suicides unrelated to drug abuse as such.

There have been various recent reviews and original articles highlighting the high rates of psychiatric disorder, particularly depression, in those who survive brain injury. ${ }^{19-21}$ There were no deaths in our study where codes for depression were given, but suicide was reported in 16 cases. As noted, the four dying of accidental poisoning may also be suicides. The population in our study is not fully representative of all head injuries admitted to hospital, but we would contend that as all ages and severities of injury were included it is useful in comparison to many previous studies which have only looked at severe traumatic brain injury. Of our original cohort of 1871 people, $1573(84 \%)$ were graded as minor injuries, and 16 to 20 were deaths by suicide, all but one of whom had been graded a minor injury. This appears a high frequency when the rate for suicide in Scotland as a whole is approximately 12/100 000. A recent Danish study ${ }^{22}$ reported the incidence of suicide in head injured people as 2.7 to 4.1 times more frequent than in the general population. Previous Finnish studies of World War II veterans had shown greater than expected suicide rates. ${ }^{23}$ With civilian populations, increased suicide rates have been described in a recent metaanalyses of five previous series ${ }^{25}$ and studies of rehabilitation services. $^{26-28}$

Studies of severe traumatic brain injury survivors have reported increased deaths from epilepsy. ${ }^{8}$ Epilepsy has been suggested as a major cause of death in those who recover with only moderate disability. ${ }^{29}$ While the incidence of seizures is increased after severe and moderate head injury, there is evidence that for mild injury the incidence is no greater than in the general population. ${ }^{30}$ In this study, seven of the eight deaths related to epilepsy were in individuals categorised as having suffered mild head injuries.

In 1979, Lewin et al reported on the outcome 10 to 24 years after severe head injury, defined as either amnesia or unconsciousness for one week or longer. ${ }^{8}$ Of those who recovered sufficiently to walk unassisted at hospital discharge, the only causes of reduced life expectancy commented upon were suicide, epilepsy, accidental drowning, and inhalation of food. ${ }^{8}$ Accidents were also reported as causes of death in two other longer term outcome reports. ${ }^{79}$ In our study there were 25 such deaths, 19 of which were of individuals who had sustained mild head injuries in 1981. It is of some interest that choking, which was a cause of death in three of our cases, was the cause of death in two of the 28 known causes of 63 deaths over 10 years in 1160 subjects enrolled in the Trauma Brain Injury Model Systems national database in the USA. ${ }^{31}$ A recent Californian study also noted a substantially increased risk of death by choking or suffocation, this being responsible for eight of 119 deaths in a traumatic brain injury population. ${ }^{32}$

Head injury occurs most commonly in young men, and low socioeconomic status and substance abuse are recognised risk factors. Thus a cohort of head injured people is not representative of the general population. This descriptive study has shown that alcohol related disorders, suicide, and accidents were common causes of death in a cohort of 1850 people injured in 1981, the great majority of whom had suffered minor injuries, during the years to 2002. In a longitudinal study of admissions to a trauma centre, it has been shown that, compared with other trauma patients, those who test positive for alcohol or other drugs at the time of admission are more likely to die from a subsequent injury. ${ }^{33}$ The investigators concluded that untreated substance abuse related injury was an untapped injury prevention opportunity and this appears applicable to those with minor head injury. The finding of 16 suicides, or 20 if accidental poisoning is included, is particularly noteworthy. Colleagues in Glasgow have recently re-emphasised the disabling sequelae of minor head injury and have demonstrated an annual incidence of disability in adults with head injuries of 100 to 150 per $100000 .{ }^{34}$ The associated increased dependence on others and reduced employment and leisure opportunities may contribute to the high incidence of suicide noted here and by others. ${ }^{23-28}$ A prospective study of suicide risk in those who have sustained head injury would be valuable and, as the Scottish Executive have stated the aim of reducing the suicide rate in Scotland by $20 \%$ by $2013,{ }^{35}$ thought should be given to targeting this group for suicide prevention interventions.

\section{Authors' affiliations \\ B Pentland, L S Hutton, Scottish Brain Injury Rehabilitation Service, Astley Ainslie Hospital, Edinburgh, UK \\ P A Jones, Department of Child Life and Health, University of Edinburgh}

Competing interests: none declared

\section{REFERENCES}

1 Goldacre MJ, Vessay MP. Health and sickness in the community. In: Weatherall DJ, Ledingham JGG, eds. Oxford textbook of medicine, 3rd ed. Oxford: Oxford University Press, 1996:39-46.

2 Krauss JF. Incidence and prevalence of, and costs associated with, traumatic brain injury. In: Rosenthal $M$, et al, eds. Rehabilitation of the adult and child with traumatic brain injury, 3rd ed. Philadelphia: FA Davis, 1999:3-18.

3 Jennett B. Head injury. In: Martyn C, Hughes RAC, eds. The epidemiology of neurological disorders. London: BMJ Books, 1998:75-95.

4 Russell WR. Disability caused by brain wounds. J Neurol Neurosurg Psychiatry 1951;14:35-9.

5 Rish BL, Dillon JD, Weiss G. Mortality following penetrating craniocerebral injuries. J Neurosurg 1983;59:775-80.

6 Walker AE, Leuchs HK, Lechtape-Gruter H, et al. Life expectancy of head injured men with and without epilepsy. Arch Neurol 1971;24:95-110.

7 Strauss DJ, Shavelle RM, Anderson TW. Long term survival of children and adolescents after traumatic brain injury. Arch Phys Med Rehabil 1998;79:1095-100

8 Lewin W, Marshall TFD, Roberts AH. Long term outcome after severe brain injury. BMJ 1979;2:1533-8.

9 Baguley I, Slewa-Younan S, Lazarus, et al. Long-term mortality trends in patients with traumatic brain injury. Brain Injury 2000;14:505-12. 
10 Miller JD, Jones PA. The work of a regional head injury service. Lancet $1985 ; i: 1141-4$

11 Jennett B, MacMillan R. Epidemiology of head injury. BMJ 1981;282:101-4

12 Dikmen SS, Machamer JE, Donovan DM, et al. Alcohol use before and after traumatic head injury. Ann Emerg Med 1995;26:167-75.

13 Kelly DF. Alcohol and head injury: an issue revisited. J Neurotrauma 1995; 12:883-90.

14 Corrigan JD, Bogner JA, Lamb-Hart GL. Substance abuse and brain injury. In Rosenthal $M$, et al, eds. Rehabilitation of the adult and child with traumatic brain injury, 3rd ed. Philadelphia: FA Davis, 1999:556-71.

15 Bombardier $\mathrm{CH}$, Rimmele CT, Zintel $\mathrm{H}$. The magnitude and correlates of alcohol and drug use before traumatic brain injury. Arch Phys Med Rehabil 2002;83:1765-73.

16 Brooks N, Symington C, Beattie A, et al. Alcohol and other predictors of cognitive recovery after head injury. Brain Injury 1989;3:235-46.

17 Kolakowsky-Hayner SA, Gouley EV, Kreutzer JS, et al. Post-injury substance abuse among persons with brain injury and persons with spinal cord injury. Brain Injury 2002;16:583-92.

18 Bombardier CH, Temkin NR, Machamer J, et al. The natural history of drinking and alcohol-related problems after traumatic brain injury. Arch Phys Med Rehabil 2003;84:185-91.

19 Hibbard MR, Uysal S, Kepler K, et al. Axis I psychopathology in individuals with traumatic brain injury. J Head Trauma Rehabil 1998;13:24-39.

20 Deb S, Lyons I, Koutzoukis C, et al. Rate of psychiatric illness 1 year after traumatic brain injury. Am J Psychiatry 1999;156:374-8.

21 Seel RT, Kreutzer JS, Rosenthal M, et al. Depression after traumatic brain injury: a national institute on disability and rehabilitation research model systems multicenter investigation. Arch Phys Med Rehabil 2003;84:177-84.

22 Teasdale TW, Engberg AW. Suicide after traumatic brain injury: a population study. J Neurol Neurosurg Psychiatry 2001;71:436-40.
23 Vauhkonen K. Suicide among the male disabled with war injuries to the brain. Acta Psychiatr Neurol Scand 1959;137(suppl):90-1.

24 Achte KA Lonnqvist J, Hillborn E. Suicide following war brain-injuries. Acta Psychiatr Scand Suppl 1971;225:1-94.

25 Harris EC, Barraclough B. Suicide as an outcome for mental disorders. Br J Psychiatry 1997;170:205-28.

26 Klonoff PS, Lage GA. Suicide in patients with traumatic brain injury: risk and prevention. J Head Trauma Rehabil 1995;10:16-24

27 Tate R, Simpson G, Flanagan S, et al. Completed suicide after traumatic brain injury. J Head Trauma Rehabil 1997;12:16-28.

28 Simpson G, Tate R. Suicidality after traumatic brain injury: demographic, injury and clinical correlates. Psychol Med 2002;32:687-97.

29 Hume Adams J, Graham DI, Jennett B. The structural basis of moderate disability after traumatic brain damage. I Neurol Neurosurg Psychiatry $2001 \cdot 71 \cdot 521-4$

30 Annegers JF, Grabow JD, Groover RV, et al. Seizures after head trauma: a population study. Neurology 1980;30:683-9.

31 Hammond FM, Wiercisiewski DR, Grattan KD, et al. Mortality following traumatic brain injury: who dies and when? Arch Phys Med Rehabil 2000:81:1260

32 Shavelle RM, Strauss D, Whyte J, et al. Long-term causes of death after traumatic brain injury. Am J Phys Med Rehabil 2001;80:510-16.

33 Dischinger PC, Mitchell KA, Kufera JA, et al. A longitudinal study of former trauma center patients: the association between toxicology status and subsequent injury mortality. J Trauma 2001;51:877-86.

34 Thornhill S, Teasdale GM, Murray GD, et al. Disability in young people and adults one year after head injury: prospective cohort study. BMJ 2000;320:1631-5.

35 Scottish Executive. Choose life: a national strategy and action plan to prevent suicide in Scotland. Edinburgh: HMSO, 2002. 